\title{
Lived Experiences of Parents' of Children with Disabilities in Swaziland
}

\author{
S'lungile K. Thwala ${ }^{1}$, Kayi Ntinda ${ }^{1}$, Buyisile Hlanze ${ }^{1}$ \\ ${ }^{1}$ Department of Educational Foundations and Management, University of Swaziland, Kwaluseni, Swaziland \\ Correspondence: S'lungile K. Thwala, Department of Educational Foundations and Management, University of \\ Swaziland, Private Bag 4 M201, Kwaluseni, Swaziland
}

Received: April 16, 2015 Accepted: May 5, $2015 \quad$ Online Published: June 25, 2015

doi:10.11114/jets.v3i4.902

URL: http://dx.doi.org/10.11114/jets.v3i4.902

\begin{abstract}
Raising a child with disability is a challenge to most parents. The study explored the lived experiences of parents of children with disabilities in Swaziland. The specific objective was to determine the challenges which parents of children with disability encounter at home, school and community, which may hinder them to work collaboratively with educators for the betterment of the children. A phenomenological design was adopted. Participants were parents (female $=16$; Males $=4$ ) who were purposively sampled from a rural setting (Maphalaleni area) whose children attended in 20 primary schools in the same area. Data were collected using semi structured interview guides and were thematically analyzed. The findings revealed that the parents encounter challenges at work, at home, school and in the community such as emotional stress, failure to cope with the children's disability and financial challenges. The study also indicated that the parents were not sure of what was expected of them in making educational decisions on behalf of their children. It also reported that parents of children with disabilities were not trained on how to cope with their children's disability and how to work with educators. The findings suggest the need for the development of training programmes which will empower parents with knowledge to better partner with educators for the benefit of the child. To address these challenges, government will need to put in place policies which will look at the needs of parents of the children with disabilities.
\end{abstract}

Keywords: challenges, special education, needs, stigmatization, inclusion, Swaziland

\section{Introduction}

Few people realize how difficult it is to be a parent until they themselves become the parents. It is even more difficult to be a parent of a child with special needs. Families with children with disabilities want the same things as other families. They want to see their children reach their full potential, they want to be included and accepted by their community and they want to enjoy things together and have fun (Baker \& Fenning, 2007). For this to happen, professionals need to recognize each child's capabilities rather than seeing only disability. They must also recognize the value and expertise of parents.

In the case of parents, the birth of a child with disabilities or the discovery that a child has disability is an intense and traumatic event. When it is learned at birth that the child is in some way abnormal, the effect on the parents can be devastating. Their initial reaction may be numbness. A parent's initial reaction is likely to be negative and similar to those related to bereavement (Blachar \& Bakar, 2007; Hill \& Rose, 2009). This is followed by a period of questioning which may go on for many years, as to why this should have happened to them. The parents may tend to blame themselves or each other (Scorgie \& Sobsey, 2000). Some may react in an emotionally and physiologically negative way to the diagnosis of their child's disability. The transition in a family with a child living with disabilities brings about significant changes in that family's social life. Some experience considerable stress, as well as feelings of depression, anger, shock, denial, self-blames guilt and confusion (Heiman, 2002). Therefore, the sequence and time needed for adjustment is different for every parent.

According to Smith (2002) parents of children with disabilities experience greater stress and a larger number of caregiving challenges, such as health problems, greater feelings of restriction, and higher levels of parental depression than parents of children without disabilities. Some families experiences difficulties in financial assistance and inadequate support from the members of the family and communities. Families of children with special needs face both the normal pressures and tensions of family life and in addition, adjustments to the presence of the child with a disability. Such families usually require assistance in order to reorganize their lives towards positive adaptation 
According to Shabalala (2000), the Swazi people like many others of different cultures, in the past looked at disability as a curse from the gods as a sign of bad omen. People with disability were excluded from all spheres of life. When a child with some disabilities was born, he or she was killed at birth. Culturally this practice was not viewed as killing, but as a way of life for dealing with abnormalities. If for some reason the child survived this ordeal daily survival was very difficult because the child would be neglected to a point of death. The very few that made it to adult life were kept hidden from general society. Stories around the birth of children born with disabilities were those of some very strange and fearsome animals with human features.

People in Swaziland are treated in different reflection. There is wide evidence of culture disrespect for those labeled disabled. Thwala (2004) states that culturally disability is seen as different from typically developing others being that people with disabilities are treated as weaker social beings. They are seen as less human to the extent that they have negative names like 'silwane'-meaning animal, 'umbungu'-a child without bones a word derived from 'sibungu' a worm. 'Sichwala' a person who cannot do things on his/her own (Shabalala 2000). Laughing at someone who with a disability was seen as a curse in African culture. The taboo is that whoever laughs inherits the disability (Thwala, 2004). In siSwati there is even a saying which says 'ungayihleki inkawu ngobe utayitala' which means do not laugh at an albino because you will give birth to the albino in the past giving birth to such children was viewed as an omen and they were regarded as disabled.

Mdziniso (2001) points out that throughout Africa people with disabilities are seen as hopeless, helpless and a curse in society, thus the African culture and belief have not made matters any easier for them. The belief of avoiding whatever is associated with evil has from early history affected people's attitude towards people with disabilities, simply because disability is associated with evil. In supporting the foregoing statements concerning the disability, Abosi (2001) states that most of these negative attitudes are more of misconceptions that stem from the lack of proper understanding of disabilities and how they affect the functioning of the affected. As a result, negative attitudes tend to constitute stumbling blocks towards the total acceptance of the disabled. Bender (2008), states that a disability may generally be defined as a condition which may restrict a person's mental, sensory, or mobility functions to undertake or perform a task in the same way as a person who does not have a disability. It does not mean that a person with a disability is unable to perform all the important requirements of a job and exceed the expectations of their employer. Some people have attitude that people with a disability are totally different and therefore to be treated differently. Unfortunately, this kind of stereotyping is in itself a form of discrimination.

It could be argued that although Swaziland has made tremendous progress in addressing the issues of children with special needs, parents of the children with special needs were not integrated into the educational activities on behalf of their children. Teachers on the other hand were given training on how to work with such children, facilities were provided to certain schools, new structures were being established, but parents of the children who are aided with all these were left out as stakeholders. They seemed not to understand how they could partner with educators. This study therefore, served to fill that gap and the findings would provide a profile of parental needs required in the development of a comprehensive training programme for parents.

\section{Material studied}

\subsection{Challenges Faced by Parents of Children with Disability}

The frustration that parents of children with special needs experience could make them distance themselves from participating in educational decisions when their children enter school. Raising a child with disability requires strength and flexibility. The child has special needs in addition to the regular needs of all children. Parents can find themselves overwhelmed by various medical, caregiving and educational responsibilities. Beresford et al. (2007), state that no matter how severe the special needs of the child is, the parents are inevitably affected in one way or the other. Most of the parents are affected emotionally. Parents often struggle with guilt; they feel as though they somehow caused the child to have disability, whether from genetics, alcohol use, stress or other logical or illogical reasons. This guilt can harm the parent's emotional health if it is not dealt with. Some parents experience a spiritual crisis or blame the other parent for not giving the support which is needed. Most parents have aspirations for their children from the time of birth and can experience severe disappointment that the child will not be an actor, a nurse, a teacher or whatever they had in mind. In order for these parents to cope with this experience they have to deal with the "death" of the perfect child who existed in their minds and learn to love and accept the child they have. They have to stop feeling ashamed or embarrassed that their child is mentally challenged. Smith (2002) concurs with (Blachar \& Bakar, 2007) that even after diagnosis; parents often face a whole gamut of emotions before they can grapple effectively with the stark truth that their child has learning disabilities

According to Beresford et al. (2007), parents of children with disability suffer from exhaustion and stress due to the degree of the amount of care needed. Feeding, clothing, bathing and diapering an infant is much easier physically than 
doing the same tasks for someone who weighs 80 pounds. Having a child with special needs can dig deeper into the pocket of the parent. Raising a child with disability may be too expensive than raising a typical child. These expenses may arise from medical equipment and supplies such as wheel chairs, medical care, care giving expenses, private education, learning equipment, tutoring or specialized transportation. Parents of children with disabilities also have to deal with complex issues related to the child's education. Either a private education must be sought or an adequate public or general education must be available. Close parental contact with the school system is vital in order for the child to receive a proper education. Parents must collaborate with teachers in order for their child's education to be effective. Teachers and parents have to be partners in the education of the child with disability (Smith, 2002). Thwala and Simelane (2010) assert that parents and other caregivers are an integral part of their children's education. For this reason they must be involved in educational decisions affecting their children from initial planning to implementation.

Parents of children with disability experience challenges which may lead them to make mistakes in upbringing of their children and which can give rise to learning difficulties and other problems. They need to be motivated to become involved in the education of their children. Parents play a greater role in the education of their children because they know their children better and are able to inform the teachers about their learning problems. They can help teachers to understand their children better and they can give advice about individual behaviour, and they can also contribute to the design and implementation of joint learning support strategies (Lewis \& Doorlag, 2006).

In Swaziland Mazibuko (2011) carried a study in the Shiselweni region to find out the perceived training and psychosocial needs of parents with special need. The study consisted of 68 parents. The findings revealed that the parents indeed encountered challenges more especially at school. The study also indicated that parents were not prepared for the inclusion of their children with disabilities in the mainstream. Regardless of the challenges, the study revealed that parents gradually cope with the nature of their children's disabilities. It also revealed that parents of children with special needs were not trained for their expected role in educational decisions. In Swaziland there is still lack of evidence to indicate that proper training and support has been given to parents. Parents of children with disability have been ignored. In the researchers' knowledge, even in the education and training sector policy of 2011 nothing is said about training of parents of children with special needs for their involvement in education decisions on behalf of their children. Parents need to be trained towards the task that they are facing, hence the need of this study which addresses the issues which have not been addressed by other studies.

\section{Methods}

\subsection{Research Design}

The study adopted a phenomenological qualitative design. A purposive non-probability sample of parents of children with disabilities, in the Maphalaleni area in the Southern Hhohho region in Swaziland was selected.

\subsubsection{Participants and Setting}

The sample size comprised of 20 purposefully selected schools from Maphalaleni area in which children with disabilities were identified. The researchers visited all the schools and went to the Head teacher's office to seek permission to use each identified child with disabilities in the study. The children with disabilities then identified their parents or caregivers. The demographic data of the participants included gender and age.

Table 1. Frequency distribution of participants by gender and age

\begin{tabular}{lll}
\hline GENDER & FREQUENCY & $\%$ \\
\hline Males & 4 & 20 \\
Females & 16 & 80 \\
Total & 20 & 100 \\
AGE & RESPONDENTS & $\%$ \\
$20-30$ & 4 & 20 \\
$31-40$ & 13 & 65 \\
$41-50$ & 3 & 15 \\
\hline
\end{tabular}

Table 1 indicates that the majority of the respondents were females comprising $80 \%$ of the respondents. It also indicates that about $20 \%$ of the 20 respondents fell in the 20-30 year age category. The age range 31-40 had the highest percentage $(65 \%)$. The next highest category was the 30-40 year bracket. The least represented category was the 41-50 years with only $15 \%$. 


\subsection{Data Collection Method and Procedure}

The researchers went to the areas where they interacted with the parents in their natural settings. Two visits were made. The first visit was done for purposes of seeking permission to conduct the study from the authorities and also to meet with, participants face to face for purposes of acquainting them with the study and also asking them to take part in the study. Convenient date for participants to be interviewed was decided on that day. Individual face to face semi-structured interviews were conducted on the second visit. Parents were requested to give a detailed description of their experiences. This included the participants' experiences at home, at work, at school and in the community in which they lived. The understanding of this helped in finding out how to help these parents to cope with this situation they are faced with and also how to help them to be involved in the education decisions on behalf of their children.

\subsection{Ethical Clearance}

Ethical clearance was obtained from the Ministry of Health and Social Welfare to conduct research. Participation in the study was purely voluntary and those who consented completed the consent forms. Pseudonyms were used to protect confidentiality and anonymity of the participants. They were also assured that their privacy would not be invaded. They were made aware that they had a right to pull out of the study if, and when they wanted to. All the elements of the study were fully disclosed verbally during the interview process. Permission to record the interviews was obtained from participants prior to conducting the interviews. The interviews were tape recorded, notes were also taken to further describe and reflected emotions observed.

\subsection{Data Analysis}

Data were thematically analyzed using the principles of thematic analysis according to Brikci and Green (2007). The approach involves six steps: familiarisation with the data, generation of tentative codes, elucidation of themes, review of themes, delineation of themes and production of the written report.

\section{Results}

From the interviews, 4 themes were identified namely; nature of disabilities, challenges faced by parents, coping strategies and strategies to support parents.

\subsection{Nature of Disability}

The results in table 6 below revealed that the highest percentage of nature of disability is intellectual 7 (35\%)

Table 2. Type of disability of the children

\begin{tabular}{lll}
\hline Type of disability & No. of children & $\%$ \\
\hline Visual Impairment & 4 & 20 \\
Physical Disability & 4 & 20 \\
Albinism & 1 & 5 \\
Epilepsy & 2 & 10 \\
Mentally challenged & 7 & 35 \\
Excess Saliva & 1 & 5 \\
Multiple & 3 & 15 \\
Total & 20 & 100 \\
\hline
\end{tabular}

It was then concluded that most children in the Maphalaleni area have mental disabilities. The parents gave different types of disabilities such as, visual impairment, mental, albinism, physical disabilities, epilepsy, excess saliva and some stated that their children had multiple disabilities. Some of the parents further stated that some children were born like that and in some the disability was discovered while they were about two years old. Make Nkhosi who had a child who had multiple disabilities had this to say,

My boy has fits, he was born like this (with his hands in-between the legs) which was a sign that he was not going to be a normal child; I started to notice that he was not well when he was about two months old. You cannot leave him alone because he can have the seizure at any time: now with the experience that I have, I can be in a position to help other parents who have a blessing of having a child like mine.

When asked to say some of the things his child can and cannot do. Mrs. Ndzingane had this to say about her child:

My child has physical disability, she cannot walk, and we discovered that she is not normal when she took long to be able to sit. She only sits for a short time, she cannot walk, and she can't even speak. She has multiple disabilities. She crawls using her hands but not for long. She cannot stand at all. You have to carry her even to the toilet. 
This is what Mr Dlamini had to say about his son. "The nature of my child's disability is albinism. He was born an albino. The causes of the disability are unknown to me, however elders believe it was hereditary from one great grandparent. He has visual impairment; he is hyper active and has skin problems".

From what the parents said about the nature of their children's disabilities, one can say that, the children have different types of disabilities. There are things which the children cannot do for themselves which they rely on their parents and caregivers for helping them. Some of the children were born with the disability, in some it is hereditary and in some it was discovered at around age one.

\subsection{Challenges Faced By Parents}

A central theme identified by the data was challenges faced by parents of children with disability. Five categories were identified under this theme, and these were social isolation, emotional stress and depression, grief and financial problems. The majority of parents indicated that they have challenges with these children at home. They said that they are failing to cope with the nature of the disability because these children demand a lot of extra care from them yet they have other family duties they need to perform. One parent even said

Hey you cannot leave Ayanda by himself because he can faint at any time. You have to give him the tablets at $7 \mathrm{am}$ and $7 \mathrm{pm}$. So you always have to be there for him. When going to a funeral, I cannot leave him behind because I always have to be besides him. So it is a big challenge. As of now we have to attend the Easter conventions, as I have a position at church (pastor's wife), I don't know where I will leave him because everyone is going to church. No one wants to remain behind so, I have to make means to go to church with him.

Most of the parents complained of being emotionally stressed by the children because they require more time, they also complained of financial problems, for instance when they have to take the children for medical check-ups. One guardian said

I did not get support from the grandfather of the child as you know that his father passed away, the child was supposed to go for another operation as his feet were not well. Due to financial problems, we could not take him to the hospital for the second operation that is why he is just like this. If we can get some financial assistance we can take him to the hospital.

One Make Khumalo said "at home we are facing a lot of challenges because my child cannot do things for himself, most of the time is dedicated to him and this affects the relationship with other family members especially the husband. He thinks that we neglect him, and give more time to the child with a disability".

Another parent said that she has less challenges at home because the family members help her in the upbringing of the child, the only challenge she has is financial. This is what she said

Wow the other children love him, they help him with any help he needs. They give him food; they make sure that he is kept clean at all times. The husband is very supportive and the grandmother is very over protective of him, she makes sure that she is always there for him; she does not allow the other children to even touch his food. When she has gone for the elderly grant, she makes sure that she brings something for Luyanda*. Yes at times he gives us hard time when it is time for taking medication and doing some exercises. But we have developed a coping strategy; we have accepted him as he is.

Another challenge the parents expressed is that of transport, they said their children were unable to go for a long distance when it is time to take them to school or to the clinic they face more problems.

Mrs Zwane remarked, "My child cannot walk, so the biggest challenge is when, I have to carry her on my back to school and to the clinic when it is time for her medical checkup. There is no transport in my area so I have to hire a car. Financially we are not able to support the child"

Another responded had this to say, "My child has to wear glasses but I cannot afford to buy him some, money is a big challenge, at times I have to take him to the eye clinic and they sometimes refer us to the chemist where medication is too expensive for us so we end up returning home empty handed"

Uncle Mabuza had this to say, "I have a problem raising the child because both her parents passed away, so we were left with the child to take care of, there is not enough food because I am self-employed, and at times my business does not go well. I am unable to provide the needs of the children more especially the one with disabilities"

From above, it can be seen that the respondents have challenges such as lack of support from family members, challenges for providing basic needs for their children, transport, medical and financial challenges.

A majority of the parents expressed their concern that they were not sure what they had to do for their children in the case of their school work. They lacked training, they wanted to work with teachers but there was too little they knew 
about helping their children in their school work. One participant had this to say,

We do not know the procedure, only if there could be someone to teach us our roles so that we can be in a position to assist out children with their school work. We are just keeping the children at school because there is nothing they can do at home, now it is better that the school fees are paid by government; we do not have the stress of paying the fees for the child in the same grade because really there is nothing that my child is doing at school

Another parent complained about the treatment his child receives from the other children at school. Most of the parents complained, saying their children were stigmatized and discriminated by the other children. They raised a concern about the way some teachers and normal children treat children with special needs. The normal children tease them and call them by their disability. Some of them call them "tinchute" (Meaning they cannot walk properly). One parent even narrated a scenario which occurred at school. This is what he had to say, "hey madam, one day I was very disappointed with the children at the school, my child is an albino, the other children put ash on their face and painted themselves with chalk then they came and mocked my child calling him a monkey. He came home crying saying that they teased him and this was so painful".

Mrs. Sithole had this to say,

At times I feel like hiding my child because he is not accepted by other children at school. I feel like keeping him at home, the other children do not want to play with him, they hate the sight of the saliva that always comes from his mouth. He is not accepted by the other children, you can see the way they react when they see him, if only I had the money, I would take him to a school just for children like him maybe there he can be able to learn without being discriminated.

Mrs Khumalo said my child has a challenge at school, as she keeps repeating classes because she cannot write well.

When asked to respond to the challenges they encounter in the community, out of the twenty respondents only one said she is content on the way the children are treated in the community, all the others complained of stigma and discrimination. Mrs Nkhosi said, 'my child is welcomed in the community, the other children play with him, when he is not able to walk home by himself, they make sure they do not leave him they carry him on their backs. They even give him food'

Nineteen parents complained on the way their children are treated in the community. They said their children are isolated, discriminated and also ridiculed. Mrs Mabuza when interviewed said, 'my child is always left out when children are chosen to participate in community events and that is paining because she wants to be part of the the other children.

Most of the children are discriminated, they call them names. Some of the children are even sexually abused by the normal people. They are stigmatized.

When asked to respond to the question that requires them to indicate the challenges they encounter at their work areas, out of the five respondents that were formally employed, two respondents said that they had no challenges at their work areas. They get the support from other staff members and supervisors. When it is time to take the children to the hospital, they are given days off. The other three respondents complained that at their work areas they had problems. Their bosses do not allow them time to take their children to the hospital. At times they are made to fill in absent from duty forms. Mrs Simelane responded by saying, 'it is difficult at my work area because when you keep on absenting yourself, it becomes a problem with the boss. 'Mrs Ndzingane, 'as I have to take my child to physiotherapy every week, really it is an inconvenience on their side. Make Mabuza said at her work place even though one can see that they have a problem they don't say it in the open. You can see by the way they treat you after you have been absent. But she does not blame them because at work you have to deliver.

\subsection{Challenges Faced by the Children with Disability}

The following categories were identified under this theme, stigma and discrimination, called by names and abuse. Parents raised a concern to treatment their children received from school and the community. Some of the teachers do not give them fair treatment, other pupils call them names they call them by their disabilities. One parent even stated that "My child was ill-treated by other children, they painted their faces with ashes and white chalks they intimidated him because of his albinism". These findings are in line with what Norwich (2003) claims. He states that for children to be given names shows that they do not belong to the society, it shows that by bringing them to school was just integration not inclusion. They lack acceptance and embracement by schoolmates.

\subsection{Coping Strategies}

Fifteen (15) out of the 20 parents said they were coping with the nature of their child's disability through God's grace, this challenging situation they have to go through needs someone who is spiritual; it is only God who can help one to be 
able to cope with the situation. Five of the parents said they were not able to cope with their child's disability. This is what some of the parents said.

Mrs Ntshangase; "I give my child all the love she needs. Being spiritual helps me a lot. When I feel depressed I just pray to God to give me strength. I also make sure that I supply the child with all the necessary equipment"

Mrs Nkhosi had this to say; "At times I find it very difficult to deal with the nature of the child, especially because there was no training that I received, but through God I overcome the challenges"

\subsection{Strategies to Support Parents}

All the participants claimed to have little knowledge of how to assist their children. They all said they never received any training from government on how to help them cope with their children's disability. They said the help that they give to their children is not adequate.

Mrs Nkhosi stated,

"When my child starts fitting at times, I shake him hard, try to give him some more air, at times it takes time for him to stop fitting, so you have to stay close to him so that he does not hurt himself at times he chews his tongue, so you have to put something so that he does not hurt himself"

Mrs Simelane responded by saying

"There is no training that I received, and the help that I give to my child is not adequate because at times I am unable to help my child when he is in pain. I cannot give him the first aid. I cannot give him the first aid she needs beside kumtfoba"

In relation to collaboration with teachers in helping their children with school work out of the 20 respondents 8 said they collaborate with the teachers, others were not sure of what was expected of them, others said they were not happy with the way teachers treat them. They complained of ill treatment of their children by the teachers, others said even the teachers are not sure of what they have to do with their children.

Mrs Dlomo had this to say; "My child is retarded, we are just keeping him at school. There is nothing the teachers can do with my child because he can't write a thing, yes I do go to school when it is time for open days, but $i$ just go there for the other children. May be if this one can go to Mzimpofu may be he can get some help and learn some other skills to help him earn a living"

Mrs Soko said; "These teachers are not trained to handle our children, yes they try but we can see that the help they give us not enough. It seems as if they themselves do not know what to do"

The respondents wished that government should help them by providing infrastructure which will be appropriate for their children to learn in the normal school, classes should be built in a way that will allow even those who are unable to walk property to attend. They also wished that government can give them training as to how to help them in the upbringing of the child and also train them how to work with teachers in assisting in their children's school work. They said government should build more schools like Mzimpofu in the communities where they will be able to take their children because they feel that what they get in the schools for the normal children is not enough This is what some of the parents said when interviewed. Mrs Khumalo had this to say,

"I think government should send disability educators to come and enlighten communities like mine about the fact that this may happen to anyone and any home. So they should consider disability as everyone's challenge. Government should also consider allocating fees to help these physically challenged children like they are doing with the OVC's"

Mr Dlamini had this to say,

Government should train and hire teachers who are specially trained to handle such children, because currently, I doubt if the special children are given the attention they deserve in the inclusive schools. Government should also raise awareness of the acceptance of children who are albinos in our society especially since we now live in fear as parents ever since the brutal killing of one child in the Shiselweni region last year in the belief of muti.

Mr Mthupha said, "I think the government can help by organizing some workshop for us where we are going to be taught how to help these children with disabilities so that we can follow the professional way of handling the child"

\section{Discussion}

The nature of the disability ranged from visual impairment, hearing impairment, walking disability, albinism, epilepsy intellectual disability hearing impairment and excessive saliva. The study revealed that some of this disability the children were born with, hereditary while others developed after they were born.

A child's disability is a triadic experience involving three way interactions among the child who experience the 
dysfunction, the family that is affected by it, and the external environment where the disability is manifested (Zilalem, 2002). Raising a child with disability is an experience which lives the parents with great stress and a number of caregiving challenges, such as more health problems, greater feelings of restriction, higher level of depression grief and financial problems. From the research findings it has been revealed that the parents encounter a lot of challenges. Some of the challenges they encounter include the following; social isolation, grief emotional stress and financial problems.

Beresford et al. (2007) states that no matter how severe the special needs of the child are, the parents are inevitably affected in one way or the other. He further states that parents often struggle with guilt; they feel as though they somehow caused the child to be disabled, whether from genetics, alcohol use, stress or other logical or illogical reasons. This guilt can harm the parent's emotional health if it is not dealt with, some parents experience a spiritual crisis or blame the other parent may be for not giving the support which is needed.

According to Dobson et al. (2001) parents of children with disability undergo the period of grieving which is similar to that of bereavement. Parents grieve for the 'death' of the perfect child who existed in their minds. They feel ashamed and embarrassed that their child is not normal. Parents may move through emotions like grief, anxiety, fear, guilt, depression and anger. Parents attach to children through core-level dreams, fantasies illusions and projections into the future. Disability dashes these cherished dreams. The impairment, not the child irreversibly spoils a parent's fundamental, heartfelt yearning. Disability shatters the dreams, fantasies, illusions and projections into the future that parents generate as pain of their struggle to accomplish basic life missions. Parents of impaired children grieve for the loss of dreams that are key to the meaning of their existence to their sense of being. Recovering from such a loss depends in one's ability to separate from the lost dream and to generate a new, more attainable dream.

Parents of children with disability face social isolation. Taking care of the child with disability requires a lot of time of the parent. As Beresford et al. (2007) stated that parents of children with disabilities sufferers from exhaustion and stress due to the degree of the amount of care needed, feeding, clothing, bathing and diapering an infant is much easier physically than doing the same tasks for someone who weighs 80 pounds. The findings are in line with what Beresford et al. (2007) said as all the respondents revealed that most of their time was spent taking care of their children with disabilities. When the respondents were asked to respond to the issue of social isolation, they all said they were now isolated from the community friends and relatives, they said their socializing time was no longer there, because they now spent a lot of time with their children. Friends have become few, relatives, some of them are supportive and some are not. Some have attitudes to the children with disabilities are among barriers preventing families from leading ordinary life as they are excluded from the community. A study conducted in Kenya by Gona, Mung'ala-Odera, Newton, $\&$ Hartley, S, (2010) revealed that families of children with disabilities felt excluded from the society due to a shortage of services and negative attitudes. The families have enough challenges to overcome, to secure the support they need without also having to cope with prejudice and isolation. They want the same things as other families, they want to be included and supported by their communities and they want to enjoy time together and have fun.

The interviews also revealed that parents of children with disability also have financial problems. Their responses were in line with (Dobson, Middleton \& Beardworth, 2001) statement where they say having a child with special needs can dig deeper into the pocket of the parent. Raising a child with disability can be too expensive than raising a typical child. These expenses may arise from medical equipment and supplies such as wheelchairs, medical care, and care giving expenses, private education, learning equipment or specialized transport. Most parents complained that they do not have enough money for giving the child the right medication or for taking the child to the hospital. For instance Mrs Gama when asked to say some challenges she had she said "due to financial problem we could not take the child to the hospital for the second operation, may be that is why his feet are like this" another parent complained that they were not employed so they were unable to give their children all the medical attention they needed.

The findings of the study revealed that normal people even today still have attitudes towards children with disabilities This is seen in the way they treat them. These attitudes are still negative in our society towards disabled people. This has to do with our culture as it has been cited before according to Shabalala (2000) that the Swazi people like many others of different cultures all over the world, in the past looked at disability as a curse from the gods as a sign of bad omen. There is wide evidence of culture disrespect for those labeled disabled. Thwala (2004) states that culturally disabled is seen as different from the normal being as a result disabled people are treated as a weaker social beings. They are discriminated, ridiculed and even not considered in the community, when then choose people to represent the community somewhere they are not considered. A majority of parents were not satisfied with the way teachers and normal children treat the children with special needs. It is therefore a need that government must train the teachers, communities of how to treat these children. Negative attitudes should not be barriers which will make these children not to live a normal life.

As it has been stated before that parents of children with disability cope with the nature of their child's disability, some 
of them stated that they cope through resilience, God's grace, courage and accepting the child as he/she is. The study revealed that resilience plays an important role to the parents of children with disabilities. Some of the parents said when they feel that the burden is beyond them, they simple prayed to God so that he can give them the strength and courage they need. The findings confirm the study conducted by Heinemann in 2002 on parents' resilience, coping and future expectations on disability. Most parents tended to react in an emotionally and physiologically negative way to the diagnosis of their child's disability but with time these parents developed coping strategies which included being spiritual, courageous and learning to accept the child with disabilities.

Parents of children with disabilities doubted if the help they were giving to their children is enough and they also doubted if the assistance their children get from teachers in the inclusive schools was enough, because they felt that even the teachers were not properly trained for teaching these children.

Another concern was that parents and teachers should work hand in hand in providing the child with the education they deserves. Some parents said they were trying to collaborate with teachers and others said that they were not sure of what was expected of them, and others raised the concern that teachers were looking down upon them. Parents need to be motivated to become involved in the education of their children these findings are in line with what Lewis and Doorlag (2006) say. Parents play a greater role in the education of their children. Parents know their children better and are able to inform the teachers with their child's learning problems. They can help teachers to understand their child better, they can give advice about individual behaviour, and they can contribute to the design and implementation of joint learning support strategies. It is for this reason that teachers and parents should work together for the betterment of the child. Parents of children with disability need to be supported by every member of the society.

All the parents complained of financial constraints towards helping their children with disabilities. They were all for the view that government must intervene. When asked if they ever received training from government or any financial assistance, again all the parents claimed to have never been to training or have ever received any financial assistance from government. This is in contrast with what other findings from other countries whereby their governments assist these parents with grants or financial services.

\section{Conclusion}

Conclusion are made that children with disabilities experience a lot of challenges in the upbringing of their children. Parents spend a lot of time trying to meet the needs of their children with disabilities. They tend to neglect those children who are said to be 'normal'. This also gives them a problem in their family relations with their siblings and spouses. They need to be supported by each and every member of the family. Parents also need to be trained/ assisted with ways in which can help them to be better able to cope with their children's disability. Parents and teachers should work hand in hand in providing the education the child deserves. As some parents were not sure of what was expected of them in making educational decisions for their children, there is a need for these parents to undergo training which will make them to be able to make sound decisions about the education of their children. Government needs to support the children financially. Stakeholders in the education sector should devise a wide range of programmes aimed at meeting the parent's needs.

\section{References}

Abosi, O. C. (2001). Trends and issues in special education in Botswana. The Journal of Special Education, 23(3), 11-16.

Baker, J., \& Fenning, R. M. (2007). Prediction of social skills in 6 year old children without development delays. American Journal of Intellectual \& Developmental Disability, 112, 375-91. http://dx.doi.org/10.1352/0895-8017(2007)112[0375:POSSIY]2.0.CO;2

Bender, W. N. (2008). Learning disabilities: Characteristics, identification and teaching strategies. Boston, Pearson

Beresford, B., Rabiee P., \& Sloper, P. (2007). Outcomes for parents with disabled children. York, Social Policy Research Unit: University of York.

Blachar, J., \& Bakar, B. (2007). Positive impact of intellectual disability on families. American Journal of Mental Retardation, 112, 330-48. http://dx.doi.org/10.1352/0895-8017(2007)112[0330:PIOIDO]2.0.CO;2

Brikci, N., \& Green, J. (2007). A guide to using qualitative research methodology. London, Health Services Research Unit: London School of Hygiene and Tropical Medicine.

Dobson, B., Middleton, S., \& Breardworth, A. (2001). The impact of childhood disability on family life. New York: Joseph Rowntree Foundation.

Gona, J. K., Mung'ala-Odera, V., Newton, C. R., \& Hartley, S. (2010). Caring for children with disabilities in Kilifi Kenya:What is the carer's experience? Child: Care, Health, and Development, 37(2), 175-183. 
Retrievedfromhttp://dx.doi.org/10.1111/j.1365-2214.2010.01124.x

Heiman, T. (2002). Parents of children with disabilities: resilience, coping and future expectations. Journal of Developmental and Physical Disabilities, 14(2), 159-171. http://dx.doi.org/10.1023/A:1015219514621

Hill, C., \& Rose, J. (2009). Parenting stress in mothers of adults with an intellectual disability: Parental cognitions in relation to child characteristics and family support. Journal of Intellectual Disability Research, 53(12), 969-980. Retrieved from http://dx.doi.org/10.1111/j.1365-2788.2009.01207.x

Kubler-Ross, E. (1980). Death the final stage of growth. New York: Simon and Schuster.

Lewis, R. B., \& Doorlag, D. H. (2006). Teaching special students in general education classrooms ( $7^{\text {th }}$ ed.) New Jersey: Pearson Merrill Prentice Hall.

Mazibuko, G. F. (2011). The received training and psychosocial needs of parents of children with special needs in Nhlangano Area, in the Shiselweni region. (Unpublished master's thesis). University of Swaziland, Kwaluseni, Swaziland.

Mdziniso, P. (2001). Teachers' attitudes, gender differences and parental attitudes towards inclusive education in primary schools in Swaziland. (Unpublished master's thesis) University of Swaziland, Kwaluseni, Swaziland.

Norwich, B. (2003). Management of inclusion, Exeter, University of Exeter: School of Education and Lifelong Learning.

Scorgie, A., \& Sobsey. B. (2000), Roecher Institute beyond the limits. Mothers caring for children with disabilities. Children and Family Series, North York, Canada: Rocher Institute.

Shabalala, Z. (2000). Practice that prevent the equitable education of children with special educational needs in Swaziland (Unpublished master's thesis). University of Swaziland, Kwaluseni, Swaziland.

Smith, R. M. (2002). Academic engagement of high school students with significance disabilities: A competent-oriented interpretation (Unpublished master's thesis).Syracuse University, New York.

Thwala, S. K. (2004). Understanding inclusion in Swaziland: An agenda for change (Unpublished master's thesis). University of Exeter, Exeter.

Thwala, S. K., \& Simelane, J. (2010). Parental partnership and national curriculum centre. Manzini: Swaziland Association of Visually Impaired Persons.

Zilalem, F. (2002). The attitudes of parents towards their blind children: A case study. Bahir Dar Town: Addis Ababa University.

\section{(c) B B}

This work is licensed under a Creative Commons Attribution 3.0 License. 